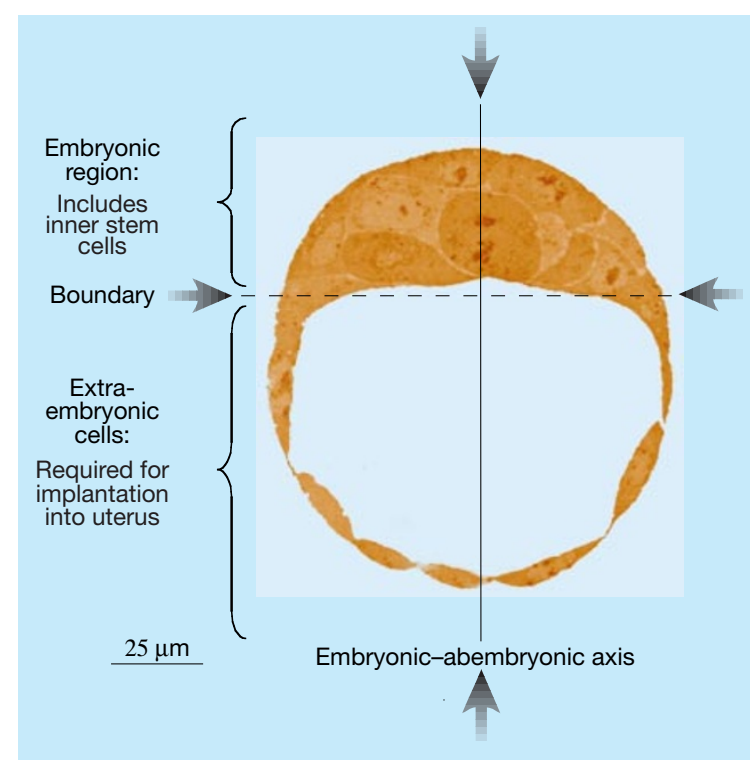

Figure 1 The 'preimplantation' mouse embryo at 3.5 days old. The figure shows the boundary between the embryonic region (which includes the inner stem cells that form the fetus) and the extraembryonic cells required for implantation of the embryo into the uterus. Piotrowska and Zernicka-Goetz ${ }^{1}$ show that the position at which the sperm enters the mouse egg during fertilization predicts this boundary. The embryonic-abembryonic axis is perpendicular to the boundary. Photograph of embryo is reproduced with permission from ref. 11. ization of one of the extraembryonic tissues is important for the future head-to-tail orientation of the body. Moreover, ZernickaGoetz's group has previously shown that the polarity of the preimplantation embryo predicts the organization of this particular extraembryonic tissue ${ }^{4}$.

Further axes are needed to orient the body from back to front and from left to right. In frogs, sperm determine the backto-front axis. Studies of the African frog Xenopus laevis have shown that fertilization sparks off a $30^{\circ}$ rotation of the outermost layer of the egg (its cortex) relative to the egg's deeper contents (its cytoplasm) ${ }^{5}$. This rotation (away from the point of sperm entry) results in the alignment of an array of cytoskeletal components - the cortical microtubules - in the yolky half of the egg. These microtubules act as tracks, along which components of the so-called Wnt signalling pathway are transported towards the prospective back (dorsal midline) of the embryo $^{6}$. The result is dorsal enrichment of the transcription factor $\beta$-catenin ${ }^{7}$, which switches on genes specific to the dorsal midline. The sperm's entry point also determines the plane of the first division of Xenopus embryos, but this appears to be accomplished through a different mechanism ${ }^{8}$.

The importance of the sperm's entry position is not unique to frogs. It sets the first cleavage plane and/or an embryonic axis in a wide range of species, including ascidians (sea squirts), molluscs and roundworms. Where studied, these animals have in common cortical or cytoplasmic reorganization, as well as periodic production of waves of calcium ions, related to the site of sperm entry ${ }^{9}$. But how similar are mice to these species?

Piotrowska and Zernicka-Goetz ${ }^{1}$ have found that the sperm's point of entry into a mouse egg determines the plane of the first division of the embryo. It also influ- ences the timing of the second cell division - the cell in the two-cell embryo that inherits the sperm entry point usually divides before the other cell. This might provide the early-dividing cell with a developmental advantage, such as preferential specialization to form one of the three cell lineages that develop during the preimplantation period - two types of extraembryonic cell, and the inner stem cells, which form the fetus.

Moreover, the authors discovered that the sperm entry position marks the boundary between the extraembryonic cells needed for implantation of the embryo into the uterus, and the inner stem cells. This boundary defines the so-called 'embryonicabembryonic' axis, which aligns perpendicular to the boundary (Fig. 1).

Piotrowska and Zernicka-Goetz have concentrated on the preimplantation period of mouse embryonic development. So their work tells us nothing about the later effects of sperm entry position on the development of the three body axes. This is a difficult issue to tackle: the mammalian embryo is very small at first (the size of a pinpoint), and it becomes inaccessible to study at just about the time of overt axis formation, because it embeds itself into the wall of the uterus. But we could speculate that, in forming the embryonic-abembryonic and the head-totail axes, the mouse embryo establishes the orientation of its body pattern before it implants into the uterus. This would be remarkable.

Further studies will be needed to determine whether or not the sperm entry site in mice also establishes the dorsal midline, as it does in frogs. In any event, finding a role for sperm in their embryonic patterning does bring mice closer to frogs and other nonmammalian species, and raises the question of whether similar molecular mechanisms underlie the effects of sperm on patterning
Daedalus

\section{David Jones}

David Jones, author of the Daedalus column, is indisposed.

in all vertebrates. Calcium waves starting from the site of sperm entry, and modest cytoplasmic movements, do occur in mouse embryos $^{10}$, as they do in frogs. But little is known about the orientation and function of the cytoskeleton during the period after fertilization in mice, much less whether there is any enrichment of Wnt-pathway components in relation to the sperm entry position. The mouse embryo is peculiar even among mammals in having no conspicuous sperm-influenced cytoskeletal organization. So, if the mouse sperm does exert its organizational role through such a mechanism, its effects are more subtle than in other species.

Finally, there is a sobering implication of the new findings ${ }^{1}$. During human infertility treatments, sperm are injected directly into human eggs. Might this be defining an embryonic axis, or even the future body pattern, of the child? With this possibility in mind, it becomes urgent to find out exactly how sperm affect mouse patterning. Although mouse embryos are more difficult to study than frogs, they are continuing to provide answers to questions that are clearly relevant to humans.

Roger A. Pedersen is in the Reproductive Genetics Unit, Department of Obstetrics, Gynecology and Reproductive Sciences, University of California, San Francisco, California 94143, USA.

e-mail: pedersen@cgl.ucsf.edu

1. Piotrowska, K. \& Zernicka-Goetz, M. Nature 409, 517-521 (2001)

2. Gardner, R. L. Curr. Top. Dev. Biol. 39, 35-71 (1998).

3. Beddington, R. S. \& Robertson, E. J. Cell 96, 195-209 (1999).

4. Weber, R. J., Pedersen, R. A., Wianny, F., Evans, M. J. \& Zernicka-Goetz, M. Development 126, 5591-5598 (1999).

5. De Robertis, E. M., Larraín, J., Oelgeschläger, M. \& Wessely, O. Nature Rev. Genet. 1, 171-181 (2000).

6. Miller, J. R. et al. J. Cell Biol. 146, 427-437 (1999).

7. Larabell, C. A. et al. J. Cell Biol. 136, 1123-1136 (1997).

8. Danilchik, M. V. \& Black, S. D. Dev. Biol. 128, 58-64 (1988).

9. Roegiers, F., McDougall, A. \& Sardet, C. Development 121, 3457-3466 (1995).

10. Deguchi, R., Shirakawa, H., Oda, S., Mohri, T. \& Miyazaki, S. Dev. Biol. 218, 299-313 (2000).

11.Pierce, G. B. Am. J. Pathol. 113, 117-124 (1983).

\section{Correction}

In Heike Langenberg's meeting report, "Meteorology: Oscillating opinion" (Nature 408, 924-925; 2000), the "new index" for the North Atlantic Oscillation, attributed to P. Yiou, refers to a poster by V. C. Slonosky and P. Yiou. The index was developed by Victoria Slonosky, Phil Jones and Trevor Davies at the University of East Anglia. Further details can be found in Slonosky, V. C., Jones, P. D. \& Davies, T. D. Int. J. Clim. 20, 1874-1897 (2000). 